\title{
INSTRUMENTAÇÃO APLICADA A PROTÓTIPO DE PENEIRA VIBRATÓRIA
}

\author{
I. K. G. VARGAS ${ }^{1}$, F. S. GUERREIRO² e R. GEDRAITE ${ }^{3}$ \\ ${ }^{1}$ Bolsista Petrobrás/UFU, discente do curso de Engenharia Química \\ ${ }^{2}$ Bolsista PPGEQ/UFU, discente do curso de Mestrado em Engenharia Química \\ ${ }^{3}$ Professor da Faculdade de Engenharia Química da UFU/MG \\ E-mail para contato: rgedraite@feq.ufu.br
}

\begin{abstract}
RESUMO - Este artigo apresenta uma contribuição acerca da investigação experimental sobre o emprego de malha de controle do adimensional referente à força-g aplicado a protótipo de peneira vibratória. O estudo foi conduzido tendo por base o processo tradicionalmente empregado em unidades de controle de sólidos. Foi definida e montada a malha de controle do adimensional de vibração (ou força-g), tendo sido escolhida como variável de processo manipulada a rotação imposta aos motovibradores instalados na peneira vibratória. Foram realizados experimentos utilizando uma bancada experimental para verificar o funcionamento da malha de controle. Os resultados obtidos sugerem um funcionamento adequado e coerente da malha de controle proposta.
\end{abstract}

\section{INTRODUÇÃO}

A utilização de sistemas eletrônicos digitais em controle e automação de processos se iniciou, praticamente, com o próprio advento dos computadores digitais. Já no começo dos anos 60, instalações industriais introduziram o computador como importante dispositivo para controle. Durante aproximadamente 20 anos, tais aplicações concentraram-se na concepção de controle centralizado, ou seja, com o computador reunindo em um único processador eventualmente redundante - todas as suas tarefas (Garcia, 2005; Seborg et al, 2005; Ogata, 2005).

Atualmente, os modernos sistemas digitais de controle distribuídos, apresentam o recurso da distribuição do processamento das informações, viabilizados pelo baixo custo dos microprocessadores, permitindo assim uma confiabilidade similar àquela obtida pelos pioneiros sistemas analógicos convencionais, ao mesmo tempo em que se oferecia toda a potencialidade dos sistemas digitais, especialmente sua flexibilidade, conferida pelas funções reprogramáveis. A estes sistemas, juntaram-se desenvolvimentos importantes em controle sequencial e combinatório (intertravamentos), dispondo-se de equipamentos designados como controladores lógicos programáveis (CLP) (Ronaes et al, 2009).

O sistema de controle de sólidos é de suma importância na operação de perfuração de poços de petróleo, sob o ponto de vista operacional, ambiental e econômico. Este fluido possui sólidos em suspensão que têm origem na ação de corte das formações rochosas pela broca de perfuração ou em sua formulação inicial, sendo classificados, de acordo com os seus componentes base, em fluidos aquosos e não aquosos. As propriedades físicas deste fluido devem ser monitoradas e corrigidas para carrear os cascalhos até a superfície; manter a 


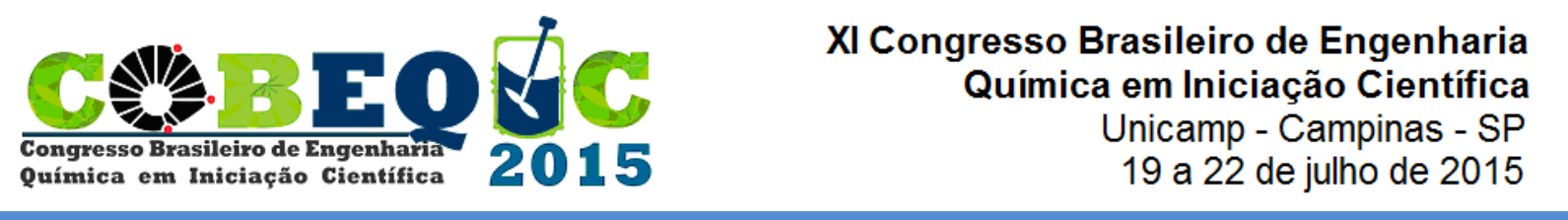

estabilidade mecânica do poço; resfriar a broca; transmitir força hidráulica até a broca; manter os cascalhos em suspensão quando sem circulação; lubrificar a coluna de perfuração entre outros. Os equipamentos utilizados em uma unidade típica de controle de sólidos para a separação sólido-líquido são divididos em três grupos sequenciais: peneiras vibratórias, bateria de hidrociclones (desareiadores e dessiltadores) e centrífuga decantadora (Lobato et al, 2011).

O objetivo deste trabalho é apresentar a instrumentação empregada em bancada experimental usada como protótipo de unidade de controle de sólidos com a finalidade de estudar o comportamento dinâmico da força-g e sua relação com a perda de fluido de perfuração arrastado juntamente com os sólidos separados (Raja et al, 2012; Guerreiro et al, 2013).

\section{MATERIAIS E MÉTODOS}

Foi utilizada como base para o desenvolvimento dos modelos apresentados neste trabalho a unidade experimental mostrada na Figura 1, a qual é formada por uma peneira vibratória com 1,65 m de comprimento, $0,81 \mathrm{~m}$ de largura e $1,0 \mathrm{~m}$ de altura, equipada com dois motovibradores e uma tela de separação, podendo esta última ser trocada quando necessário; um tanque de $500 \mathrm{~L}$ com agitação para alimentação da suspensão à peneira; um tanque de descarga de $200 \mathrm{~L}$ para coleta do material passante e uma bomba centrífuga para transportar este líquido passante de volta ao tanque de alimentação.

Figura 1 - Unidade de recuperação de fluido de perfuração: (1) - tanque de $500 \mathrm{~L}$ com agitador; (2) - calha de alimentação; (3) - tela de peneiramento; (4) - balde para o material retido; (5) - tanque de descarga de $200 \mathrm{~L}$; (6) - Bomba centrífuga; (7) - dois motovibradores;

(8) - acelerômetro; (9) - placa de aquisição de dados e (10) - inversor de frequência.

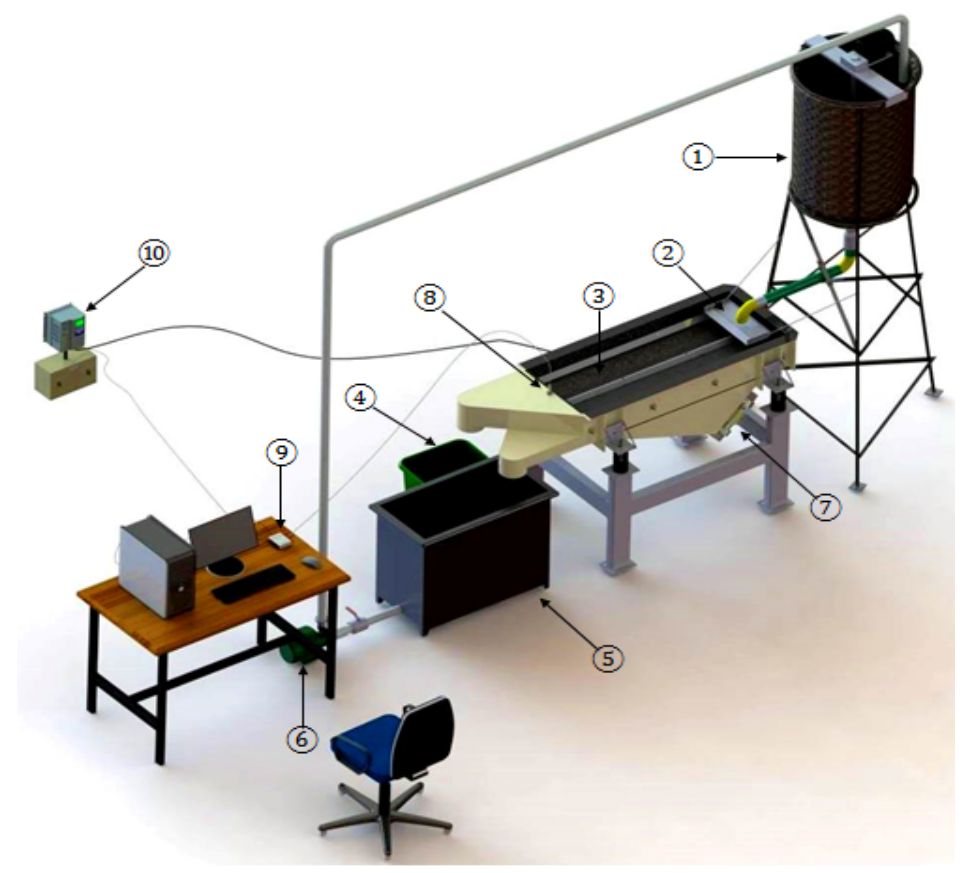


A peneira está equipada com dois motovibradores com $0,75 \mathrm{cv}$ de potência cada um. Esses foram montados de maneira a gerar movimentos em sentidos opostos de forma a garantir a vibração adequada da peneira, impondo movimento linear ao material alimentado sobre a tela de peneiramento. Para controlar a intensidade da vibração imposta ao sistema, ajustou-se a frequência de rotação dos motovibradores por meio de um inversor de frequência da marca WEG modelo CFW700 (Liu; Gao, 2012).

Para medir a vibração, foi utilizado um acelerômetro piezelétrico da marca PCB Piezoeletronic modelo 646B00, mostrado na Figura 2, o qual foi responsável por enviar um sinal na faixa de 4 a $20 \mathrm{mAcc}$ a um computador através da placa de aquisição de dados da National Instruments modelo USB 6008 (Figura 3). A grandeza do sinal é dada em força-g numa faixa de 0 a $10 \mathrm{~g}_{\mathrm{rms}}$.

Figura 2 - Acelerômetro usado para aquisição de dados referente à vibração imposta à peneira.

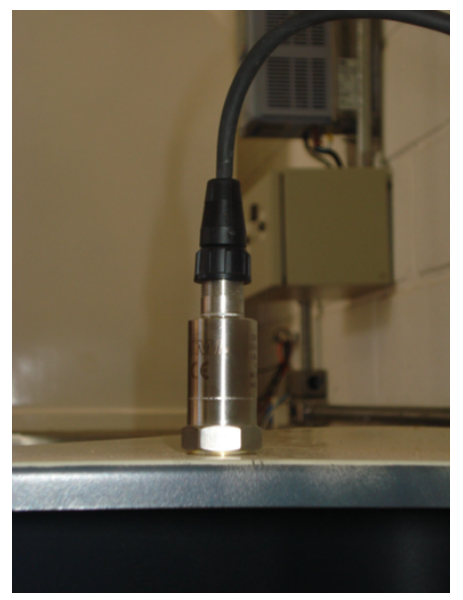

Figura 3 - Placa para aquisição dados do sinal enviado pelo acelerômetro para o controle de força-g.

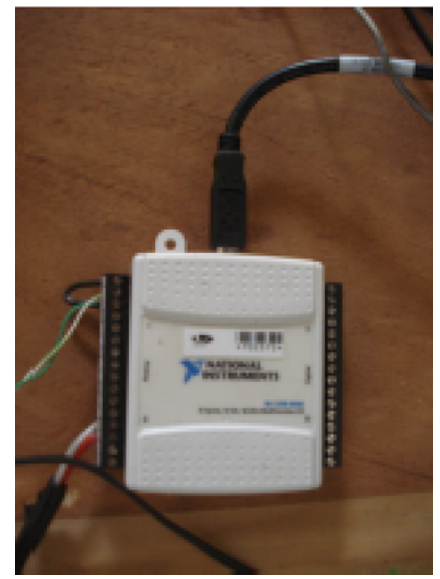

O programa utilizado para auxiliar a coleta de dados e monitoramento da unidade experimental foi o Labview 2013 da National Instruments, cuja programação é apresentada na Figura 4. Nela, o sinal de corrente gerado pelo acelerômetro era coletado em um taxa da ordem de milisegundos e condicionado em uma faixa de 1 a $5 \mathrm{~V}$. O sistema coletava 1000 valores por segundo. Era calculada a média dos valores coletados para cada intervalo de tempo de 1 segundo e convertida para força-g. Também era possível selecionar um valor de rotação para funcionamento dos motovibradores através do sinal enviado ao inversor de frequência. Para a realização dos experimentos foi necessário estabelecer um valor prédeterminado (set-point) de força-g. Mas à medida que a suspensão era adicionada à peneira, a massa aumentava e, consequentemente, a força-g diminuía. Foi criado um controlador proporcional para compensar este distúrbio. Os dados coletados eram exportados para uma planilha do Excel. 
Figura 4 - Diagrama de blocos correspondente à malha de controle configurada.

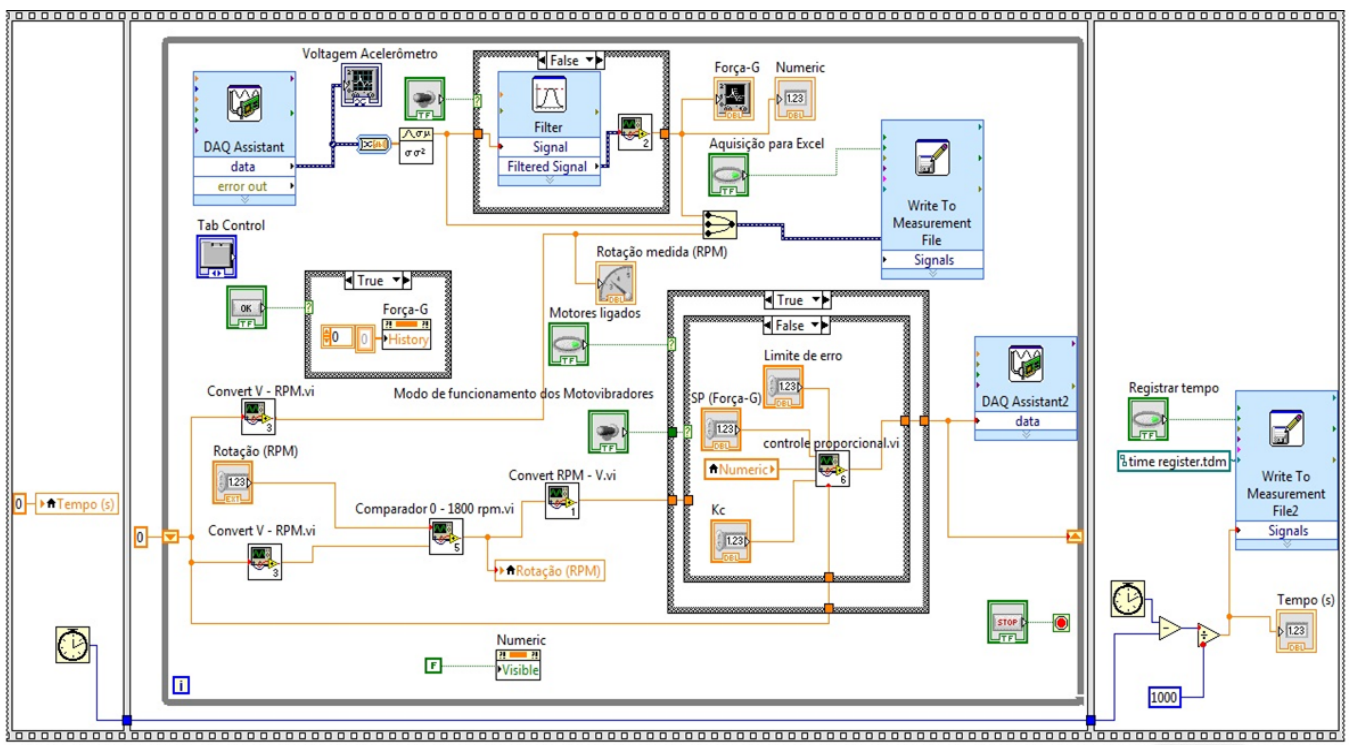

\section{RESULTADO E DISCUSSÃO}

O comportamento temporal da variável de processo controlada (número adimensional força-g) para a peneira vibratória estudada é apresentada na Figura 5. O valor médio do adimensional de força-g foi de aproximadamente 1,00 e o desvio padrão correspondente foi 0,04. A variabilidade apresentada pela variável de processo em questão foi inferior a 7,7\%. O comportamento temporal da variável manipulada é apresentado na Figura 6. Com base nas Figuras 5 e 6, pode-se perceber que a malha de controle proposta atuou de maneira coerente e adequada para compensar a tendência de diminuição do valor do adimensional de força-g à medida que o material sólido granular era alimentado sobre a tela da peneira.

Figura 5 - Comportamento temporal do adimensional de força-g.

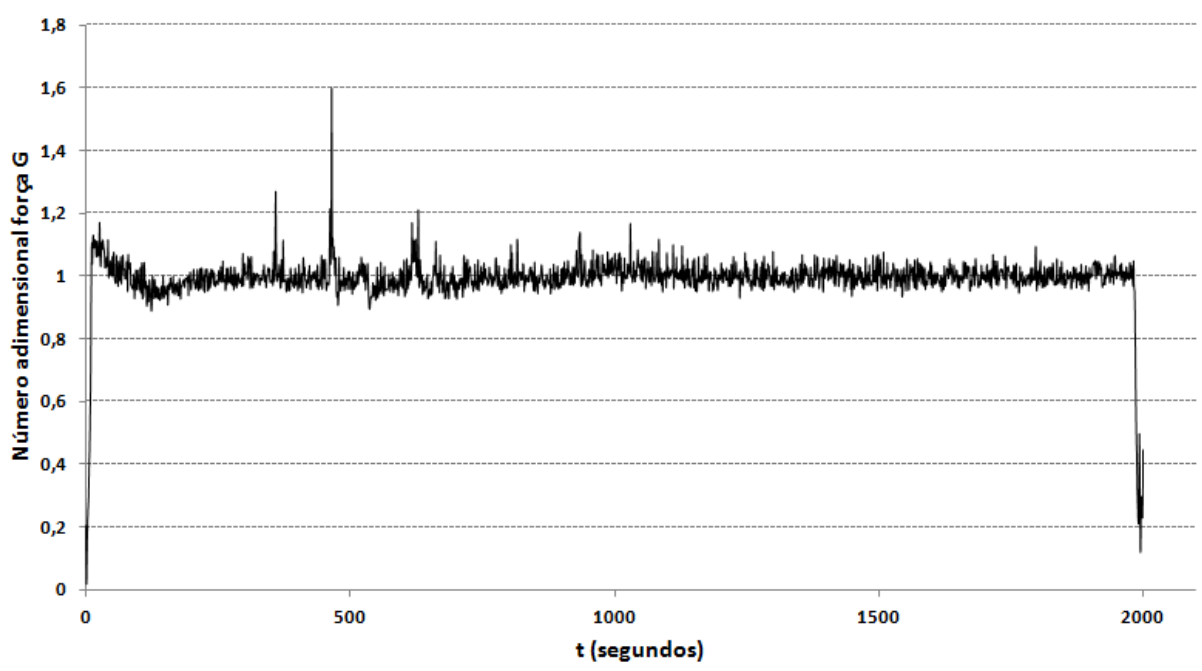




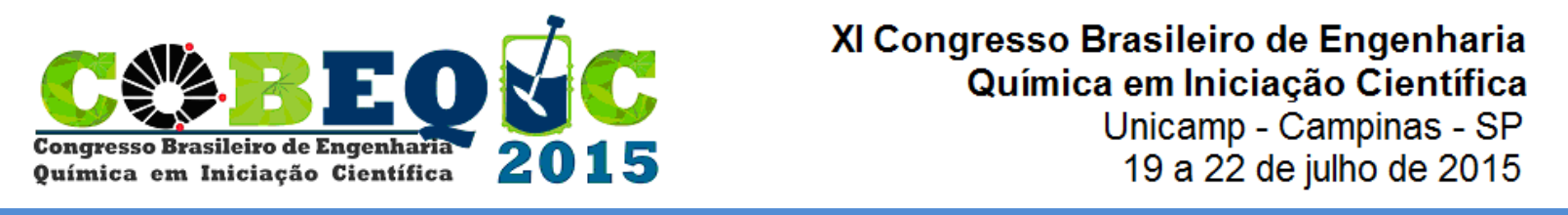

Figura 6 - Comportamento temporal da rotação dos motovibradores

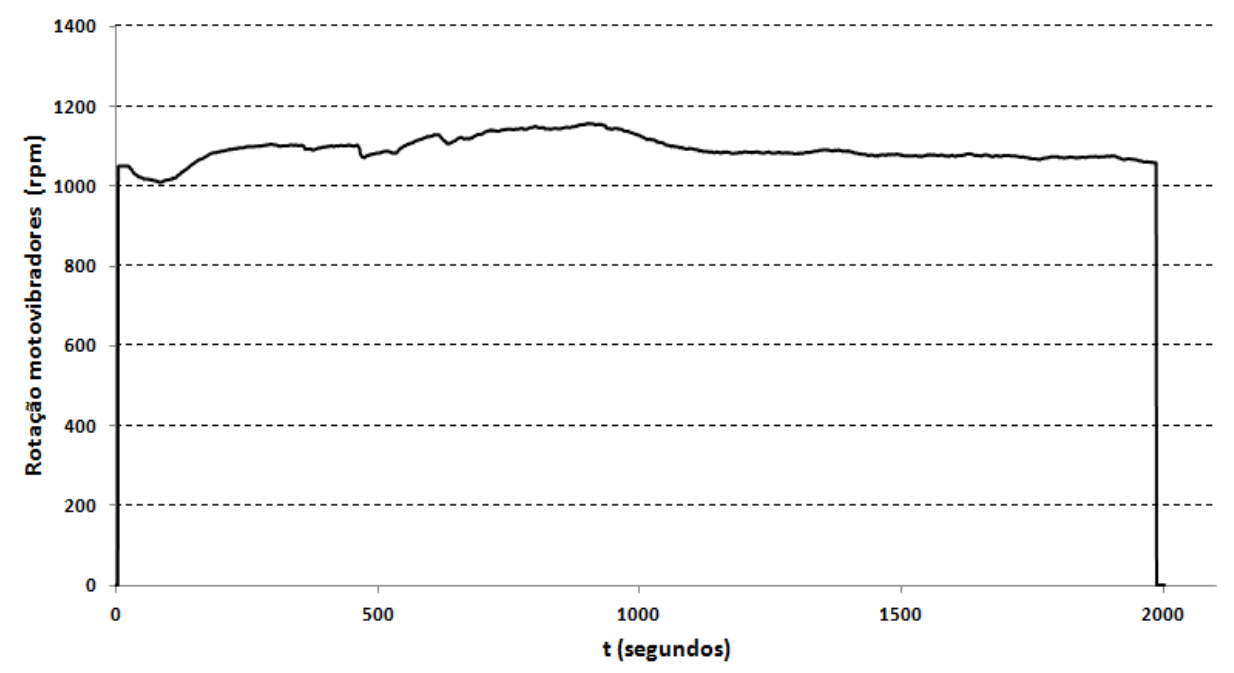

Entre os instantes $\mathrm{t}=88$ segundos e $\mathrm{t}=909$ segundos, o sistema de controle atuou e foi proporcionando um aumento gradual na intensidade do sinal de saída enviado aos motovibradores, de maneira a manter o número adimensional da força-g constante. Após o instante $\mathrm{t}=909$ segundos, o sistema de controle voltou a diminuir a intensidade de correção, muito provavelmente em função de o distúrbio ter diminuído de intensidade. Um aspecto importante na operação da bancada experimental foi a constatação experimental de que o material solido dissolvido acabava por ser descarregado do tanque principal de alimentação logo no início da operação, havendo dificuldade em se manter a suspensão bem misturada ao longo do tempo de realização do experimento.

\section{CONCLUSÃO}

Considerando os resultados obtidos no experimento anteriormente apresentado, pode-se concluir que o sistema de controle e respectiva instrumentação funcionaram de maneira coerente e adequada.

Diante dos resultados apresentados, pode-se concluir que a peneira vibratória poderá ter o seu modelo matemático dinâmico identificado com base em experimentos propostos futuramente especificamente para tal finalidade, podendo este ser usado como ferramenta de analise de processo.

Com base neste modelo identificado, poder-se-á avaliar o impacto que alterações préestabelecidas no valor do número adimensional força-g teriam sobre o teor de umidade arrastado pelo material sólido granular retido sobre a tela da peneira.

O principal beneficio que poderá resultar da aplicação do modelo no processo está relacionado ao melhor controle da operação, minimizando a perda de fluido de perfuração e maximizando a vida útil da tela da peneira.

\section{AGRADECIMENTOS}


Os autores agradecem à UFU, ao CNPq e à PETROBRÁS pelos recursos concedidos e apoio em pesquisas no projeto referente ao termo de cooperação $\mathrm{N}^{\circ} 0050.0078502 .12 .9$.

\section{REFERENCIAS}

GARCIA, C. Modelagem e Simulação de Processos Industriais e de Sistemas Dinâmicos. 2005. EDUSP, São Paulo.

GUERREIRO, F. S., QUEIROZ, C. G., NEIRO, S. M. S., SÁ, C. H. M., GEDRAITE, R. (2013). Contribution to the study of dynamic behaviour of a shale shaker typically used in drilling fluid treatment unit. Anais do V Encontro Nacional de Hidráulica de Poços de Petróleo e Gás, Teresópolis - RJ, 5 a 8 de agosto de 2013.

LIU, T.; GAO, F.(2012). Industrial Process Identification and Control Design. SpringerVerlag, London - UK.

LOBATO, F. S., OLIVEIRA-LOPES, L. C., GEDRAITE, R., NEIRO, S. M. S., MURATA, V. Identificação de modelos para unidades de recuperação do fluido de perfuração. In: IV Encontro Nacional de Hidráulica de Poços de Petróleo e Gás, Foz do Iguaçu - PR, 2011.

OGATA, K. Engenharia de Controle Moderno. Rio de Janeiro: Prentice Hall do Brasil, $3^{\text {a }}$ edição, 2000.

Raja, V., Chase, G. G., Jones, B. N. and Geehan, T. (2012). Computational Modeling and Experiments on Shale Shaker Performance. Proceedings of AADE Fluids Technical Conference and Exhibition. Houston, Texas.

RONAES, E., VIK, S. E., TAUGBOL, K., SJAHOLM, A.; KAAGESON-LOE, N. (2009). Remote real-time monitoring of particle size distribution in drilling fluids during drilling of a depleted HTHP reservoir. Proceedings of SPE/IADC, pp. 1-11, Manama, Bahrain, 26-28 October.

SEBORG, D. E., EDGAR, T. F. and MELLINCHAMP, D. A. (2005). Process Dynamics and Control. Wiley, 2nd Ed., USA. 